\title{
Exclusive Substitutional Nitrogen Doping on Graphene Decoupled from an Insulating Substrate
}

\author{
Juan Carlos Moreno-López,* Filippo Fedi, Giacomo Argentero, Marco Carini, Johnny Chimborazo, \\ Jannik Meyer, Thomas Pichler, Aurelio Mateo-Alonso, and Paola Ayala*
}

Cite This: J. Phys. Chem. C 2020, 124, 22150-22157

Read Online

ABSTRACT: The on-surface synthesis of atomically flat $\mathrm{N}$-doped graphene on oxidized copper is presented. Besides circumventing the almost standard use of metallic substrates for growth, this method allows producing graphene with $\sim 2.0$ at $\% \mathrm{~N}$ in a substitutional configuration directly decoupled from the substrate. Angle-resolved photoemission shows a linear energy-momentum dispersion where the Dirac point lies at the Fermi level. Additionally, the $\mathrm{N}$ functional centers can be selectively tailored in $\mathrm{sp}^{2}$ substitutional configuration by making use of a purpose-made molecular precursor: dicyanopyrazophenanthroline $\left(\mathrm{C}_{16} \mathrm{H}_{6} \mathrm{~N}_{6}\right)$.

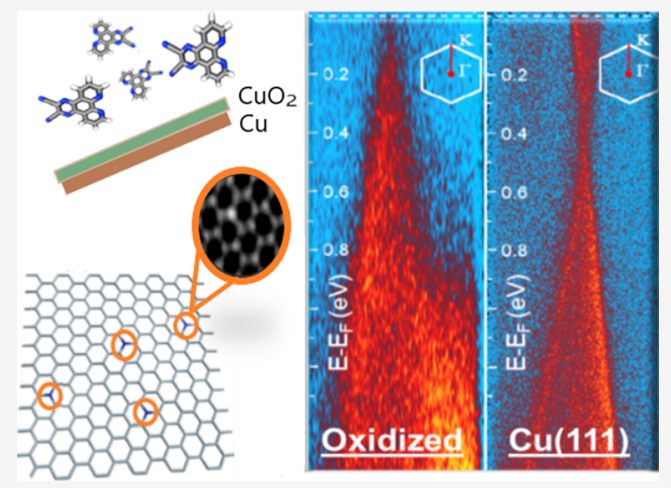

\section{INTRODUCTION}

The Nobel Prize recognition to the discovery of graphene in 2010 boosted the efforts to produce this two-dimensional (2D) material, which opened a new paradigm of relativistic condensed matter physics. One of the most remarkable features of graphene originates from the linear dispersion of its $\pi$ and $\pi^{*}$ bands at the Dirac point in the vicinity of the Fermi level, which accounts for the description of pristine graphene as a zero-gap semiconductor. ${ }^{1,2}$ This material with outstanding physical properties has inspired the seek for a mechanism to control its behavior in a tunable manner, and nonsurprisingly, studies on the functionalization of graphene with the presence of heteroatoms such as N, B, and Si have appeared in an exponential way. ${ }^{3-6}$ For instance, nitrogendoped graphene (N-graphene) was first reported in 2009 from the pyrolysis of pyridine and ammonia in the arc discharge of graphite electrodes, ${ }^{7}$ but later studies have optimized its growth with a wide scope of techniques. ${ }^{8-13}$ Several applications of $\mathrm{N}$-graphene have already been tested toward a new generation of batteries, ${ }^{14-16}$ oxygen reduction, ${ }^{17}$ hydrogen generation, ${ }^{18}$ biosensors, ${ }^{19,20}$ supercapacitors, ${ }^{21,22}$ and quantum dots. ${ }^{23,24}$ Ideally, the method used for the synthesis of graphene should be chosen according to the intended application.

Especially in applications where the control of the electronic properties plays a critical role in the performance, the growth mechanism should be understood. Different $\mathrm{N}$ bonding environments can affect the local electronic structure, so for $\mathrm{N}$-graphene, the goal is to gain control on the electronic properties incorporating substitutional functional centers and the least possible vacancy-related defects. Also, the work function and carrier concentration of $\mathrm{N}$-graphene are changed by the dopants. ${ }^{25,26} \mathrm{~A}$ decoupling from the surface can also open interesting application pathways. With all this in mind, on-surface synthesis can be one of the most versatile strategies to build such complex low-dimensional materials and use them as-grown. To some extent, this method can be related to chemical vapor deposition (CVD), in which vapors of pyrazine, $^{7}$ ammonia, ${ }^{27}$ acetonitrile, ${ }^{14}$ and triazine ${ }^{28}$ among others have been used, but making $\mathrm{N}$-graphene with mainly substitutional configuration is still extremely challenging with such methods. Studies carried out with ion implantation have shown that $\mathrm{N}$ can be incorporated onto the surface, ${ }^{29,30}$ and further work has proven the incorporation of the heteroatoms at the local level with techniques such as scanning tunneling microscopy, which require a metallic surface to ease characterization. ${ }^{26,28,31}$ However, CVD can offer a scalability advantage, but the effect of catalytic surfaces used must be carefully taken into account. For instance, a metallic substrate can negatively interfere with the performance of graphene, and this is the reason why fabricating graphene-based electronic devices requires several transfer processes to place either directly onto insulators or onto high $\kappa$-dielectric materials. ${ }^{32-34}$ These

Received: July 14, 2020

Revised: August 31, 2020

Published: August 31, 2020 
processes undermine the quality of graphene and make it prone to wrinkling, ${ }^{33-35}$ explaining, in turn, the considerable amount of research still looking for a clear route to fabricate high-quality graphene on suitable substrates. ${ }^{13,36-39}$

Herein, we report an on-surface synthesis method to grow $\mathrm{N}$-graphene using a nitrogen-rich polycyclic aromatic hydrocarbon as feedstock, namely, dicyanopyrazophenanthroline (see Figure 1). ${ }^{40}$ This derivative possesses a high $\mathrm{C} / \mathrm{N}$ ratio

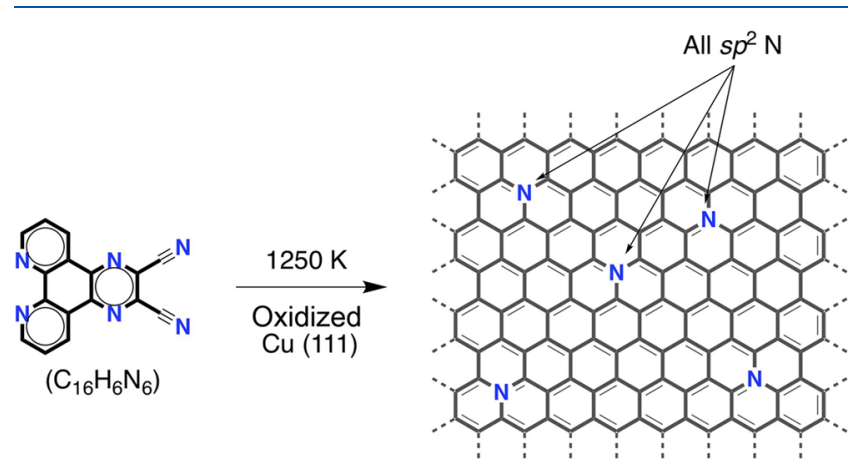

Figure 1. Dicyanopyrazophenanthroline $\left(\mathrm{C}_{16} \mathrm{H}_{6} \mathrm{~N}_{6}\right)$ molecule was used as a precursor for the synthesis of $\mathrm{N}$-graphene. Its structure has favored the formation of $\mathrm{N}$ substitutional configuration. Left: $\mathrm{C}_{16} \mathrm{H}_{6} \mathrm{~N}_{6}$ molecule. Right: N-graphene.

(16:6): all the nitrogen atoms are incorporated into the aromatic framework in $\mathrm{sp}^{2}$ - or other $\mathrm{sp}-\mathrm{N}$ configuration, and it can be deposited by sublimation. The molecular deposition studies on different surfaces include single-crystalline $\mathrm{Cu}(111)$, polycrystalline copper foil, and the corresponding oxidized surfaces. Remarkably, the use of dicyanopyrazophenanthroline leads to the exclusive incorporation of $\mathrm{N}$ in $\mathrm{sp}^{2}$ configuration within the graphene hexagonal lattice from the first step with a doping level of $\sim 2.0$ at $\%$, which represents at least double the amount of substitutional atoms reported for $\mathrm{N}$-graphene grown on an insulating material (Table 1). It is important to remark that this value corresponds to substitutional doping if it is compared to the literature, where the doping values reported combine the portion of different bonding environments. Furthermore, N-graphene grown on insulating oxidized $\mathrm{Cu}(111)$ shows an energy-momentum dispersion with the Dirac point lying at the Fermi level, demonstrating that the oxide layer decouples graphene from the substrate.

\section{METHODS}

A dicyanopyrazophenanthroline $\mathrm{C}_{16} \mathrm{H}_{6} \mathrm{~N}_{6}$ molecule was used as $\mathrm{C} / \mathrm{N}$ feedstock, and its synthesis and capability to induce the incorporation on the graphene network have been reported elsewhere. ${ }^{40}$ We have grown $\mathrm{N}$-doped graphene, and its spectroscopic characterization has been carried out in situ in ultrahigh vacuum (UHV) via photoemission spectroscopy (PES) in different energy ranges as explained later, as well as with low-energy electron diffraction (LEED). PES was performed using a dedicated spectrometer equipped with a monochromated $\mathrm{Al} \mathrm{K} \alpha$ source $(1486.6 \mathrm{eV})$ and a Scienta RS4000 analyzer. It is also equipped with a He II lamp operating at $40.8 \mathrm{eV}$ for ultraviolet PES. Polycrystalline copper foil $(0.025 \mathrm{~mm})$ from Alfa Aesar and a $\mathrm{Cu}(111)$ single crystal $(\phi 5 \mathrm{~mm} \times 2 \mathrm{~mm})$ from $\mathrm{MaTecK} \mathrm{GmbH}$ were used as starting materials. For the sample preparation, the $\mathrm{Cu}(111)$ single crystal and the $\mathrm{Cu}$ foil were cleaned by $\mathrm{Ar}^{+}$sputtering for several cycles for $60 \mathrm{~min}$ and then annealed at $800 \mathrm{~K}$ for another $60 \mathrm{~min} . \mathrm{C}_{16} \mathrm{H}_{6} \mathrm{~N}_{6}$ was subsequently deposited on the clean $\mathrm{Cu}(111)$ and the clean $\mathrm{Cu}$ polycrystalline copper foil at room temperature in UHV using a Knudsen cell working at $\sim 400 \mathrm{~K}$. The deposition rates were monitored using a quartz micro balance. To obtain oxidized surfaces, the samples were exposed to air during $5 \mathrm{~min}$, while additional metallic $\mathrm{Cu}(111)$ and $\mathrm{Cu}$ foil samples were kept under UHV conditions. The following annealing treatment at $1250 \mathrm{~K}$ was performed on all samples. Scanning transmission electron microscopy (STEM) measurements were performed with a Nion UltraSTEM 100 electron microscope operated at $60 \mathrm{keV}^{41}$ The TEM grid preparation was carried out using the polymethylmethacrylate (PMMA)-based technique, which included the coating of graphene with PMMA, etching of the copper foil with $\mathrm{FeCl}_{3}$ to place the suspended graphene on TEM grids, and, finally, the PMMA removal with acetone. ${ }^{42}$ Scanning electron microscopy was carried out using a Zeiss Supra 55 VP microscope.

\section{RESULTS AND DISCUSSION}

The use of $\mathrm{C}_{16} \mathrm{H}_{6} \mathrm{~N}_{6}$ results in the effective growth of graphene on the substrates in question. Nevertheless, significant differences appear looking in their spectroscopic responses. First, our samples show graphene portions ranging from 0.5 to $2 \mu \mathrm{m}$ independently from the surface where they were grown, which hints that the grain size distribution is linked to the feedstock rather than to the nature of the substrate (see a representative scanning electron micrograph of this type of material in Figure 2). Further microscopy measurements were carried out by STEM. This was carried out for analytical and structural inspection on suspended graphene transferred to TEM grids in the feasible cases as later described together with the surface structural analysis via LEED and ARPES. With these pieces of information, we are able to gather valuable information on the electronic dispersion (momentum vs energy) of $\mathrm{N}$-graphene on $\mathrm{Cu}(111)$ compared to the oxidized counterpart. All these results are explained below in detail.

Focusing first on the molecular precursor that is a derivative of the phenanthroline molecule, featuring an extended $\pi$ conjugated system, it provides the initial advantage that it bears

Table 1. Reported Studies on N-Graphene Directly Grown on Insulators or High $\kappa$-Dielectric Materials

\begin{tabular}{|c|c|c|c|}
\hline feedstock & $\mathrm{N}($ at $\%)$ & N-configuration & reference \\
\hline molecular nitrogen $\left(\mathrm{N}_{2}\right)$ & N.A. & pyridinic/pyrrolic & 36 \\
\hline ammonia $\left(\mathrm{NH}_{3}\right)$ & N.A & pyridinic & 37 \\
\hline ammonia $\left(\mathrm{NH}_{3}\right)$ & 0.1 & pyrrolic/sp ${ }^{2}$ & 38 \\
\hline hexaazotriphenylene $\left(\mathrm{C}_{18} \mathrm{~N}_{12}\right)$ & 7.8 & pyridinic/pyrrolic/sp ${ }^{2}$ & 39 \\
\hline pyridine $\left(\mathrm{C}_{5} \mathrm{H}_{5} \mathrm{~N}\right)$ & 0.6 & $\mathrm{sp}^{2}(2.5 \mathrm{eV})^{a}$ & 13 \\
\hline dicyanopyrazophenanthroline $\left(\mathrm{C}_{16} \mathrm{H}_{6} \mathrm{~N}_{6}\right)$ & 2.0 & $\mathrm{sp}^{2}(1 \mathrm{eV})^{a}$ & here \\
\hline
\end{tabular}

${ }^{a}$ Observable fwhm at the $\mathrm{N} 1 \mathrm{~s}$ in XPS. 


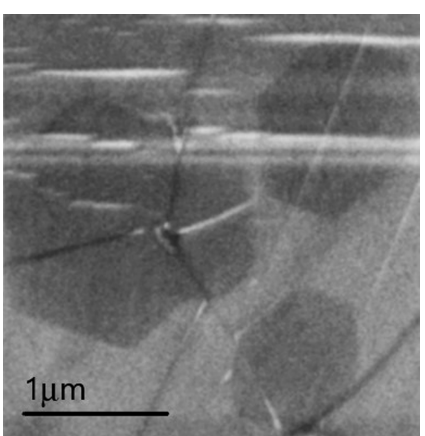

Figure 2. Representative SEM micrograph of N-graphene grown on $\mathrm{Cu}$ foil showing the $2 \mathrm{D}$ material grown over surfaces with a cross section ranging from 0.5 to $2 \mu \mathrm{m}$.

multiple nitrogen sites susceptible to coordinate with the metal, including a strong chelating phenanthroline ring, a bridging pyrazine ring, and cyano groups ${ }^{43,44}$ (see Figure 1). These coordination sites are crucial to prevent the desorption of the molecular precursor during the high-temperature onsurface synthesis process we applied. In particular, at these temperatures, the molecules decompose and rearrange on the surface to provide the most stable lattice, given the local chemical composition under the given conditions. Here, the chemical nature of the feedstock will dominate the decomposition rates that in turn will affect key factors such as the local composition. However, a mechanistic overview of the reaction or any intermediate cannot be matched with wellestablished polymerization mechanisms.

The process was followed in-situ monitoring the cleanliness, purity, and, afterward, the molecular transformation with the use of XPS with an $\mathrm{Al} \mathrm{K} \alpha(1486.6 \mathrm{eV})$ monochromated source. Survey scans and a closer inspection to the C, N, and $\mathrm{Cu}$ regions were performed for all samples. Also, the $\mathrm{O}_{1 \mathrm{~s}}$ core level signal was taken into account for the appropriate cases. First, analyzing the processes using the $\mathrm{Cu}(111)$ surface, Figure 3, shows the $\mathrm{C} 1 \mathrm{~s}$ and $\mathrm{N}$ 1s core level spectra recorded directly after the deposition of the $\mathrm{C}_{16} \mathrm{H}_{6} \mathrm{~N}_{6}$ molecule (top) and after the transformation into $\mathrm{N}$-graphene (bottom). The Shirley background was subtracted in these spectra before deconvolution. ${ }^{45}$ The $\mathrm{C}$ 1s signal corresponding to the substrate with $\mathrm{C}_{16} \mathrm{H}_{6} \mathrm{~N}_{6}$ as-deposited reveals four components at 283.7, 284.3, 284.9, and $285.6 \mathrm{eV}$, which are ascribed correspondingly to the $\mathrm{C}-\mathrm{N}, \mathrm{C}-\mathrm{C}, \mathrm{C}=\mathrm{N}$, and $\mathrm{C} \equiv \mathrm{N}$ bonding environments, respectively. ${ }^{46-48}$ The ratio between the integrated area of these peaks $(2: 3: 2: 1)$ is in good agreement with the proportions in the chemical structure of the $\mathrm{C}_{16} \mathrm{H}_{6} \mathrm{~N}_{6}$ molecule (Figure $\mathrm{S} 1$ in the Supporting Information). It is important to remark that the absence of a notorious shift of the C $1 \mathrm{~s}$ peak (and implicitly of its components) confirms that our material corresponds basically to monolayer coverage (Figure S2 in the Supporting Information). On the other hand, the two components observed in the $\mathrm{N}$ 1s spectrum (see Figure $3 \mathrm{~b}$ ) can be attributed to $\mathrm{N}=\mathrm{C}(397.1 \mathrm{eV})$ and $\mathrm{N} \equiv \mathrm{C}(398.5 \mathrm{eV}){ }^{46,49}$ The surface described so far corresponds to the raw deposition of the molecules at room temperature, but various postdeposition annealing treatments were tested. For annealing temperatures lower than $1100 \mathrm{~K}$, only minor changes were observed in XPS, which lead us to use higher temperatures for the molecular transformation into $\mathrm{N}$-graphene (see spectra recorded at different temperatures in Figure S3 in the Supporting Information). Once the annealing temperature reached $1250 \mathrm{~K}$, a major change was evident. In particular, the $\mathrm{C} 1 \mathrm{~s}$ peak in Figure 3a narrows down significantly in Figure 3c,
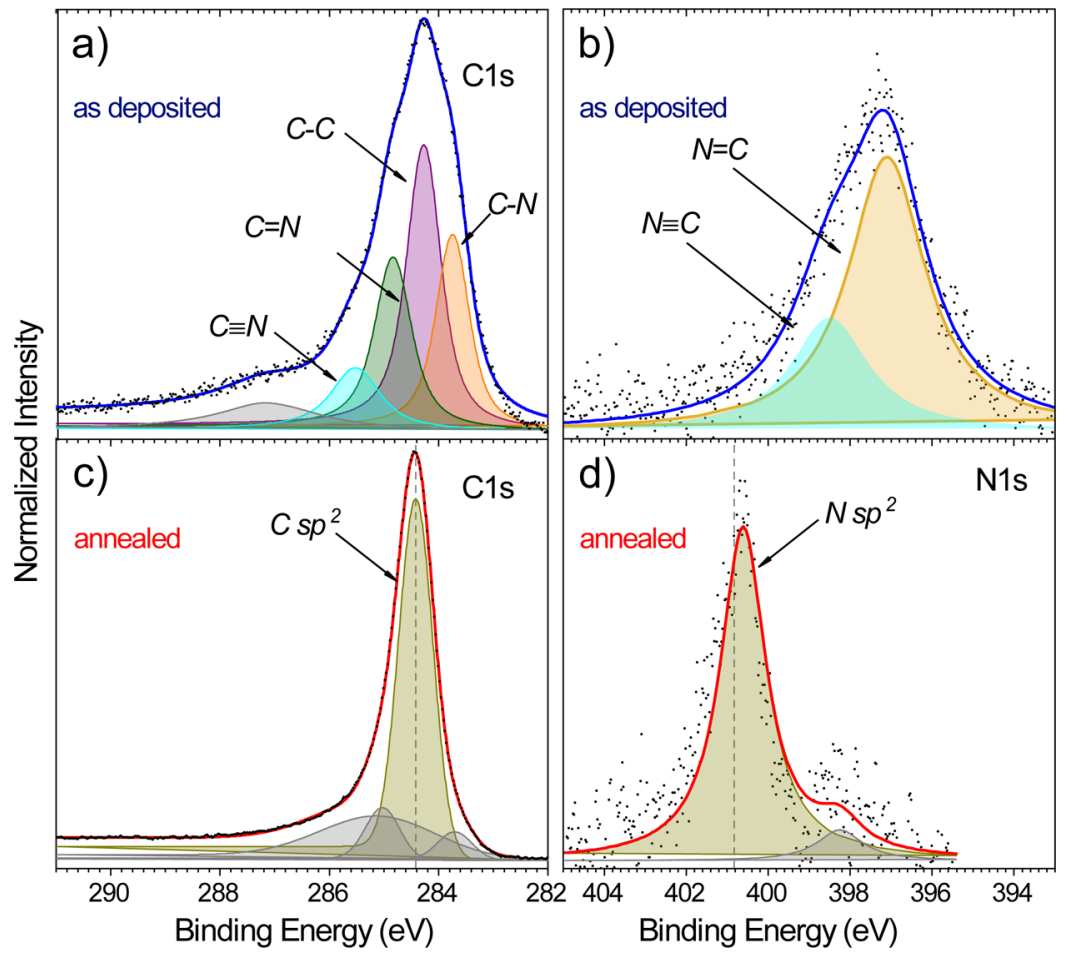

Figure 3. $\mathrm{C} 1 \mathrm{~s}$ and $\mathrm{N} 1 \mathrm{~s}$ XPS spectra of $\mathrm{C}_{16} \mathrm{H}_{6} \mathrm{~N}_{6}$ on $\mathrm{Cu}(111)$ "as-deposited" (a,b) and after annealing at $1250 \mathrm{~K}$ (c,d). The experimental data are represented as dots, and the fitted data are represented as solid lines. Note that the low binding energy peak besides the corresponding substitutional $\mathrm{N}$ is related to Mo $3 \mathrm{p}_{3 / 2}$ present in the sample holder. 
suggesting the fading of at least two components, leading to a single chemical environment. Note that previous work on $\mathrm{sp}^{2}$ $\mathrm{C}$ systems has allowed revealing the characteristic spectra for different structures including graphene. ${ }^{6,50,51}$ Here, the spectra have been fitted with a Voigtian profile by taking into account a Gaussian contribution associated with the resolution of our spectrometer with the monochromated X-ray source. In this specific case, this $\mathrm{C}$ 1s spectrum can be fitted almost exclusively by a single peak at $284.4 \mathrm{eV}$ with a full width at half-maximum (fwhm) of $0.8 \mathrm{eV}$, which is in very good agreement with the values corresponding to graphene in synchrotron and lab-based photoemission experiments. ${ }^{13,52,53}$ Furthermore, a shift of the $C$ 1s can be expected because of the $\mathrm{N}$ incorporation on the lattice and the interaction with the specific metallic substrate, but the largest contribution to this core response arises from the $\mathrm{sp}^{2}$-hybridized $\mathrm{C}$ atoms. Regarding the $\mathrm{N}$ incorporation into the lattice of $\mathrm{N}$-graphene grown on the $\mathrm{Cu}(111)$ substrate, Figure $3 b, d$ shows the core level $\mathrm{N}$ 1s spectra where the components below $399 \mathrm{eV}$ recorded straight after the molecular deposition correspond to the nitrilic and pyridinic bonding environments in agreement with the structure of the molecule. ${ }^{40}$ On the other hand, after annealing, the $\mathrm{N}$-graphene spectrum is notoriously different. A considerable number of studies reported in the literature have focused on $\mathrm{N}$-graphene, but in seldom cases, both local and bulk sensitive methods have successfully proven to be a $\mathrm{N}$ incorporation profile. Table 1 shows a summary of the reports on $\mathrm{N}$-graphene directly grown on oxides or high $\kappa$-dielectric materials. In contrast with those and other reports in the literature on $\mathrm{N}$-graphene, where the assignment of exclusive bonding environments is clearly limited by resolution, here, the $\mathrm{N}$ 1s spectrum shows a single peak at $400.6 \mathrm{eV}$ with an fwhm of $1 \mathrm{eV}$. Only in this way, the spectra can be safely ascribed almost exclusively to substitutional nitrogen because it is obtained from a Voigtian profile that considers the intrinsic Gaussian experimental resolution and the lifetime Lorentzian broadening. ${ }^{54}$ Furthermore, by analyzing the relative areas of the $\mathrm{N} 1 \mathrm{~s}$ and $\mathrm{C} 1 \mathrm{~s}$ peaks (corrected by the atomic cross sections), ${ }^{55}$ a $\mathrm{N}$ content of 2.0 at $\%$ has been found in average in these N-graphene samples. The XPS results obtained for the polycrystalline foil are very similar to those obtained from the $\mathrm{Cu}(111)$ single crystal from the content and bonding configuration points of view. Also, the $\mathrm{N}$-graphene samples grown on the oxidized surfaces were examined in XPS. The $\mathrm{C}$ $1 \mathrm{~s}$ and $\mathrm{N} 1 \mathrm{~s}$ responses have consistently shown a shift toward lower binding energies $(\sim 0.15 \mathrm{eV})$ and $\sim 2.0$ at $\% \mathrm{~N}$ in substitutional configuration (Figure S4 in the Supporting Information). An advantage of using the foil is that preparing microscopy grids for further observation is achieved with lesser effort. With this material, we performed annular dark-field (ADF) imaging in STEM pursuing an atom-by-atom identification. $^{56}$ The collected signal from the atoms is originated from Rutherford scattering, and it increases with the atomic number, so we are able to identify the dopants clearly. Figure 4 shows an atomically resolved ADF-STEM image of the $\mathrm{N}$-graphene grown from a polycrystalline foil. The images show a regular pattern of atoms forming a hexagonal lattice with a nearest-neighbor distance of $0.14 \mathrm{~nm}$ characteristic between the $\mathrm{C}$ atoms. ${ }^{26,57} \mathrm{~A}$ careful observation of Figure 4 unveils a higher contrast in two atoms of the image. The line profiles of these atoms are depicted in the inset of Figure 4a. As expected, $\mathrm{N}$ atoms $(Z=7)$ show a higher contrast than $\mathrm{C}$ atoms $(Z=6)$ in the ADF-STEM images. Moreover, the
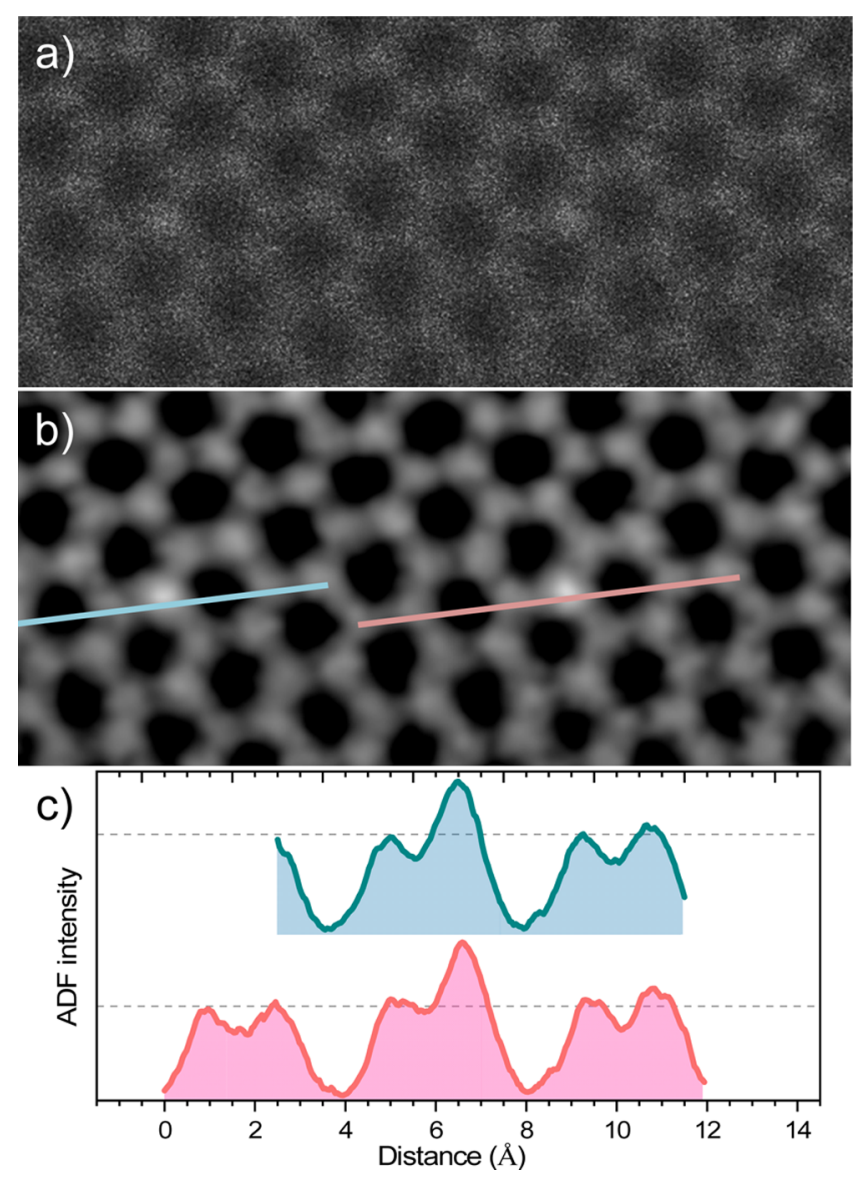

Figure 4. Medium-angle ADF-STEM image of graphene: (a) asacquired and (b) filtered image using $4 \times 4$ Gaussian blur. (c) Line profiles acquired along the two lines depicted in panel (b).

relative ADF-STEM intensity between the $\mathrm{N}$ and the $\mathrm{C}$ atoms $(4: 3)$ is in very good agreement with previously reported work. $^{56}$ The $\mathrm{N}$ atoms observed in the micrographs are clearly in substitutional configuration (see Figure S5 in the Supporting Information).

We keep in mind that the main focus has been to work toward a one-step method that enables us to obtain a highquality $\mathrm{N}$-graphene that can be used directly after the molecular transformation. Previous studies have shown that the presence of oxygen on copper can significantly influence the final quality of graphene and this is often related to the oxygen concentration during synthesis. ${ }^{58-62}$ Our on-surface method offers a very controlled alternative to explore the advantage of using an oxide instead of a metallic surface to produce $\mathrm{N}$-graphene. More specifically to the synthesis, after $\mathrm{C}_{16} \mathrm{H}_{6} \mathrm{~N}_{6}$ deposition, the samples were exposed to air for $5 \mathrm{~min}$ and then placed again under UHV conditions. This hints that the substrate plays a key role for a controllable adsorption of the molecular species and also during the on-surface synthesis. $^{63,64}$ The $5 \mathrm{~min}$ exposure to air is a good compromise between quality and decoupling of graphene from its substrate, which represents a significant advancement to the state-of-theart on $\mathrm{N}$-graphene synthesis. The analysis corresponding to this material is shown in Figure 5. The panel a shows the C 1s spectrum of the $\mathrm{N}$-graphene on the oxidized $\mathrm{Cu}(111)$ with its corresponding deconvolution. Compared to graphene on $\mathrm{Cu}(111)$ (Figure 3c), a shift toward lower binding energies $(0.1 \mathrm{eV})$ is observed, which is the first hint toward a low 

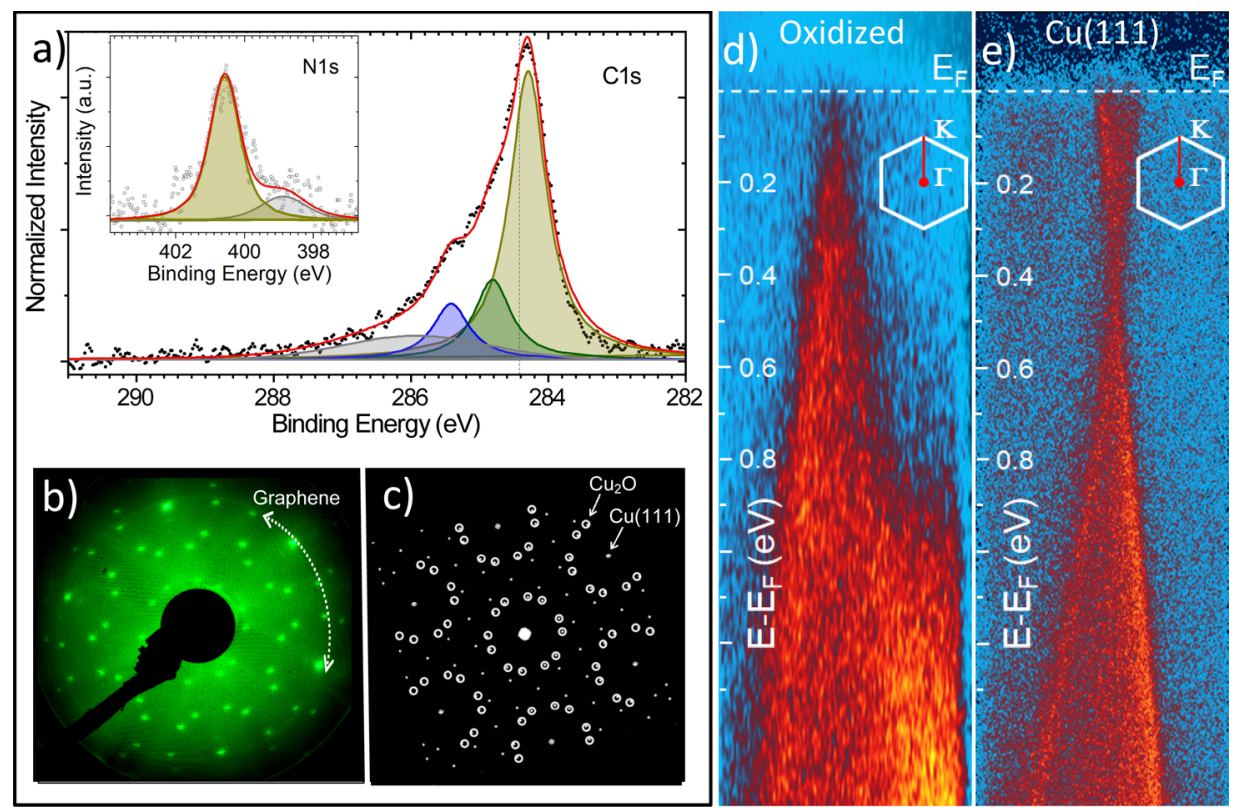

Figure 5. (a) XPS C 1s deconvoluted core level spectrum recorded on $\mathrm{N}$-doped graphene grown on oxidized $\mathrm{Cu}(111)$. The inset shows the $\mathrm{N} 1 \mathrm{~s}$ core level spectrum with the corresponding deconvolution. (b) Experimental LEED pattern of polycrystalline graphene on oxidized $\mathrm{Cu}(111)$ acquired at $94.2 \mathrm{eV}$ at nearly normal incidence. The dashed curved arrow indicates the position of the graphene ring. (c) Simulated LEED pattern. The visible spots in the experimental pattern have been highlighted. The white arrows point at one of the $\mathrm{Cu}(111)$ and $\mathrm{Cu}_{2} \mathrm{O}$ spots. The $\mathrm{ARPES}$ image of $\mathrm{N}$-graphene on oxidized $\mathrm{Cu}(111)(\mathrm{d})$ and $\mathrm{Cu}(111)$ (e), acquired with a photon energy of $40.8 \mathrm{eV}$ (He II) along the $\overline{\Gamma K}$ direction. The white dotted line shows the position of the Fermi level.

interaction of the $\mathrm{N}$-graphene with the substrate. This has been reported for graphene on oxidized $\mathrm{Cu}(111)^{9,34,65}$ grown from CVD. Further looking at the $\mathrm{C} 1 \mathrm{~s}$, the response corresponding to $\mathrm{N}$-graphene on crystalline $\mathrm{Cu}(111)$, in Figure $3 \mathrm{c}$, is very different from the spectrum of $\mathrm{N}$-graphene on oxidized $\mathrm{Cu}(111)$, which has additional components. Besides the peak at $284.3 \mathrm{eV}$ corresponding to $\mathrm{sp}^{2}$-hybridized $\mathrm{C}$ atoms on oxidized $\mathrm{Cu}(111)$, the minor components at 284.8 and 285.4 $\mathrm{eV}$ reflect the presence of carbon in another binding environment, which might be attributed to $\mathrm{C}-\mathrm{OH}$ and $\mathrm{C}-$ $\mathrm{O}$ bonds, ${ }^{66-68}$ justified by the formation of molecular species on the surface with $\mathrm{O}$ and $\mathrm{H}$ atoms that are present after the feedstock's decomposition. Furthermore, the LEED diffraction pattern in Figure $5 \mathrm{~b}$ obtained after annealing the $\mathrm{C}_{16} \mathrm{H}_{6} \mathrm{~N}_{6}$ at $1250 \mathrm{~K}$ deposited on oxidized $\mathrm{Cu}(111)$ shows well-defined spots, suggesting a long-range order over extended zones of the surface. To disambiguate the interpretation of this diffraction pattern and gain deeper insight into the surface structure, we have performed LEED simulations using LEEDpat software ${ }^{69}$ (Figure 5c). With this, it was possible to associate the LEED spots to a surface reconstruction described by the matrix $\left(\begin{array}{cc}3 & 2 \\ -1 & 2\end{array}\right)$ and its three equivalent rotational domains. This surface reconstruction has been interpreted as a distorted $\mathrm{Cu}(100)-(\sqrt{2} \times \sqrt{2}) \mathrm{R} 45^{\circ}-\mathrm{O}$ layer on the $\mathrm{Cu}(111)$ substrate. $^{34,70,71}$ Note that a careful observation of Figure $5 \mathrm{~b}$ unveils a circular ring typical of polycrystalline graphene just above the $1 \times 1$ diffraction spots of $\mathrm{Cu}(111)$. For the sake of comparison, the graphene grown on the clean $\mathrm{Cu}(111)$ was inspected. Also, in this case, the diffraction pattern corresponds to the characteristic ring from polycrystalline graphene combined with the first0order diffraction of $\mathrm{Cu}(111)$ (Figure S6 in the Supporting Information).

To further analyze the electronic performance of the $\mathrm{N}$ graphene on oxidized $\mathrm{Cu}(111)$, ARPES measurements where performed with a photon energy of $40.8 \mathrm{eV}$ (He II source). The fingerprint of graphene in ARPES on $\mathrm{Cu}$ and other metals is well established in the literature. Graphene on $\mathrm{Cu}(111)$ shows a Dirac point residing at $0.4 \mathrm{eV}$ below the Fermi level (corresponding to n-type doping). ${ }^{34,72-76}$ Our N-graphene sample grown on $\mathrm{Cu}(111)$ shows the Dirac point residing at $0.43 \mathrm{eV}$ below the Fermi level (Figure 5e). Only for graphene decoupled from the substrate, the intrinsic Dirac cone of pristine graphene can be retained, and this has been shown in the literature with methods such as decoupling by gold intercalation under graphene grown on nickel, ${ }^{77}$ the growth on polycrystalline samples finding decoupled flakes by microARPES, ${ }^{78}$ and by actually oxidizing $\mathrm{Cu}$ prior to the growth, ${ }^{34}$ where an additional flat band is observed at $\sim 0.8 \mathrm{eV}$ below the $E_{\mathrm{F}}$, which originates from the hybridization of the $\mathrm{Cu}_{4 \mathrm{~s}}$ and the $\mathrm{O}_{2 \mathrm{p}}$ states. In Figure $5 \mathrm{~d}$, the linear dispersion of the $\pi$ and $\pi^{*}$ bands at the vicinity of the Dirac point along the $\overline{\Gamma K}$ direction in the Brillouin zone is observed. Note that the Dirac point here is around $0.1 \mathrm{eV}$ below $E_{\mathrm{F}}$, which is associated to the charge transfer that arises from the $\mathrm{N}$-substitution. We expect distribution of the dopants to be random but it is mainly substitutional, differing from previous studies that correlate the local densities around $\mathrm{N}$ impurities versus the spectral densities given by ARPES ${ }^{79}$ in samples where a larger $\mathrm{N}$ concentration can be attained but not necessarily exclusively on direct substitutional fashion. Moreover, this confirms that the presence of copper oxide favors the decoupling of $\mathrm{N}$-graphene from its metallic substrate. ${ }^{80-82}$

\section{CONCLUSIONS}

In summary, we have proved the feasibility of on-surface synthesis of $\mathrm{N}$-graphene using $\mathrm{C}_{16} \mathrm{H}_{6} \mathrm{~N}_{6}$ as the molecular precursor, which has allowed obtaining a material with nearly exclusive substitutional $\mathrm{N}$, which is in turn decoupled from its 
catalytic surface. Our method has been proven for singlecrystalline $\mathrm{Cu}(111)$ and polycrystalline copper foils, which represent a technologically relevant low-cost option. We have shown that it is possible to grow $\mathrm{N}$-graphene with $\sim 1.4-2$ at \% $\mathrm{N}$ in substitutional configuration. Further studies on the tunability of this doping level would enhance the applicability of doped graphene grown by this method even more. Our ARPES measurements show that $\mathrm{N}$-graphene is decoupled from its substrate, opening encouraging prospect for its direct growth on other relatively inexpensive high $\kappa$-dielectric materials.

\section{ASSOCIATED CONTENT}

\section{(s) Supporting Information}

The Supporting Information is available free of charge at https://pubs.acs.org/doi/10.1021/acs.jpcc.0c06415.

Molecular structure of the dicyanopyrazophenanthroline molecule; C 1s XPS spectra for mono- and multilayer coverages; C $1 \mathrm{~s}$ XPS spectra as a function of postdeposition annealing temperature; $\mathrm{C} 1 \mathrm{~s}$ and $\mathrm{N} 1 \mathrm{~s}$ XPS spectra after annealing at $1250 \mathrm{~K}$; medium-angle ADF-STEM images of N-graphene; and LEED of $\mathrm{N}$ graphene on metallic and oxidized $\mathrm{Cu}(111)$ (PDF)

\section{AUTHOR INFORMATION}

\section{Corresponding Authors}

Juan Carlos Moreno-López - Faculty of Physics, University of Vienna, 1090 Wien, Austria; ㅇo orcid.org/0000-0003-10788607; Email: juan.moreno@univie.ac.at

Paola Ayala - Faculty of Physics, University of Vienna, 1090 Wien, Austria; (1) orcid.org/0000-0002-5851-6638; Phone: +43 (0)1 4277 72626; Email: paola.ayala@ univie.ac.at

\section{Authors}

Filippo Fedi - Faculty of Physics, University of Vienna, 1090 Wien, Austria

Giacomo Argentero - Faculty of Physics, University of Vienna, 1090 Wien, Austria; (1) orcid.org/0000-0003-0406-8208

Marco Carini - POLYMAT, University of the Basque Country UPV/EHU, E-20018 Donostia-San Sebastian, Spain

Johnny Chimborazo - Faculty of Physics, University of Vienna, 1090 Wien, Austria

Jannik Meyer - Faculty of Physics, University of Vienna, 1090 Wien, Austria; (i) orcid.org/0000-0003-4023-0778

Thomas Pichler - Faculty of Physics, University of Vienna, 1090 Wien, Austria; (1) orcid.org/0000-0001-5377-9896

Aurelio Mateo-Alonso - Faculty of Physics, University of Vienna, 1090 Wien, Austria; Ikerbasque, Basque Foundation for Science, 48013 Bilbao, Spain; 이 orcid.org/0000-0002-53162594

Complete contact information is available at:

https://pubs.acs.org/10.1021/acs.jpcc.0c06415

\section{Notes}

The authors declare no competing financial interest.

\section{ACKNOWLEDGMENTS}

P.A. acknowledges the contribution of the CA COST Action no. CA15107 (MultiComp). M.C. and A.M.-A. acknowledge support of the Basque Science Foundation for Science (Ikerbasque), POLYMAT, the University of the Basque
Country (Grupo de Investigación GIU17/054 and SGIker), Gobierno Vasco (BERC program), and Gobierno de España (Ministerio de Economia y Competitividad CTQ2016-77970R). M.C. and A.M.-A. thank technical and human support provided by SGIker of UPV/EHU and European funding (ERDF and ESF). A.M.-A. acknowledges that this project has received funding from the European Research Council (ERC) under the European Union's Horizon 2020 research and innovation Programme (grant agreement no. 722951).

\section{REFERENCES}

(1) Geim, A. K.; Novoselov, K. S. The rise of graphene. Nat. Mater. 2007, 6, 183-191.

(2) Chen, X.; Wu, B.; Liu, Y. Direct preparation of high quality graphene on dielectric substrates. Chem. Soc. Rev. 2016, 45, 20572074.

(3) Zhu, J.; Park, H.; Podila, R.; Wadehra, A.; Ayala, P.; Oliveira, L.; He, J.; Zakhidov, A. A.; Howard, A.; Wilkins, J.; et al. Magnetic properties of sulfur-doped graphene. J. Magn. Magn. Mater. 2016, 401, $70-76$.

(4) Anand, B.; Karakaya, M.; Prakash, G.; Sai, S. S. S.; Philip, R.; Ayala, P.; Srivastava, A.; Sood, A. K.; Rao, A. M.; Podila, R. Dopantconfiguration controlled carrier scattering in graphene. RSC $A d v$. 2015, 5, 59556-59563.

(5) Susi, T.; Kotakoski, J.; Kepaptsoglou, D.; Mangler, C.; Lovejoy, T. C.; Krivanek, O. L.; Zan, R.; Bangert, U.; Ayala, P.; Meyer, J. C.; et al. Silicon-Carbon Bond Inversions Driven by $60-\mathrm{keV}$ Electrons in Graphene. Phys. Rev. Lett. 2014, 113, 115501.

(6) Podila, R.; Chacón-Torres, J.; Spear, J. T.; Pichler, T.; Ayala, P.; Rao, A. M. Spectroscopic investigation of nitrogen doped graphene. Appl. Phys. Lett. 2012, 101, 123108.

(7) Panchakarla, L. S.; Subrahmanyam, K. S.; Saha, S. K.; Govindaraj, A.; Krishnamurthy, H. R.; Waghmare, U. V.; Rao, C. N. R. Synthesis, structure, and properties of boron-and nitrogendoped graphene. Adv. Mater. 2009, 21, 4726-4730.

(8) Sheng, Z.-H.; Shao, L.; Chen, J.-J.; Bao, W.-J.; Wang, F.-B.; Xia, $\mathrm{X}$.-H. Catalyst-free synthesis of nitrogen-doped graphene via thermal annealing graphite oxide with melamine and its excellent electrocatalysis. ACS Nano 2011, 5, 4350-4358.

(9) Koch, R. J.; Weser, M.; Zhao, W.; Viñes, F.; Gotterbarm, K.; Kozlov, S. M.; Höfert, O.; Ostler, M.; Papp, C.; Gebhardt, J.; et al. Growth and electronic structure of nitrogen-doped graphene on $\mathrm{Ni}(111)$. Phys. Rev. B 2012, 86, 075401.

(10) Usachov, D.; Vilkov, O.; Grüneis, A.; Haberer, D.; Fedorov, A.; Adamchuk, V. K.; Preobrajenski, A. B.; Dudin, P.; Barinov, A.; Oehzelt, M.; et al. Nitrogen-doped graphene: efficient growth, structure, and electronic properties. Nano Lett. 2011, 11, 5401-5407.

(11) Jin, Z.; Yao, J.; Kittrell, C.; Tour, J. M. Large-scale growth and characterizations of nitrogen-doped monolayer graphene sheets. ACS Nano 2011, 5, 4112-4117.

(12) Wang, H.; Maiyalagan, T.; Wang, X. Review on recent progress in nitrogen-doped graphene: synthesis, characterization, and its potential applications. ACS Catal. 2012, 2, 781-794.

(13) Yang, J.; He, W.; Jiang, Q.; Chen, Z.; Ju, H.; Xue, X.; Xu, Z.; $\mathrm{Hu}$, P.; Yu, G. Hydrogen-Dominated Metal-Free Growth of Graphitic-Nitrogen Doped Graphene with n-type transport behaviors. Carbon 2020, 161, 123-131.

(14) Reddy, A. L. M.; Srivastava, A.; Gowda, S. R.; Gullapalli, H.; Dubey, M.; Ajayan, P. M. Synthesis of nitrogen-doped graphene films for lithium battery application. ACS Nano 2010, 4, 6337-6342.

(15) Qiu, Y.; Li, W.; Zhao, W.; Li, G.; Hou, Y.; Liu, M.; Zhou, L.; Ye, F.; Li, H.; Wei, Z.; et al. High-rate, ultralong cycle-life lithium/ sulfur batteries enabled by nitrogen-doped graphene. Nano Lett. 2014, 14, 4821-4827.

(16) Zhou, X.; Wan, L.-J.; Guo, Y.-G. Binding SnO2Nanocrystals in Nitrogen-Doped Graphene Sheets as Anode Materials for LithiumIon Batteries. Adv. Mater. 2013, 25, 2152-2157. 
(17) Yang, H. B.; Miao, J.; Hung, S.-F.; Chen, J.; Tao, H. B.; Wang, X.; Zhang, L.; Chen, R.; Gao, J.; Chen, H. M.; et al. Identification of catalytic sites for oxygen reduction and oxygen evolution in $\mathrm{N}$-doped graphene materials: Development of highly efficient metal-free bifunctional electrocatalyst. Sci. Adv. 2016, 2, No. e1501122.

(18) Fei, H.; Dong, J.; Arellano-Jiménez, M. J.; Ye, G.; Kim, N. D.; Samuel, E. L.; Peng, Z.; Zhu, Z.; Qin, F.; Bao, J.; et al. Atomic cobalt on nitrogen-doped graphene for hydrogen generation. Nat. Commun. 2015, 6, 8668.

(19) Wang, Y.; Shao, Y.; Matson, D. W.; Li, J.; Lin, Y. Nitrogendoped graphene and its application in electrochemical biosensing. ACS Nano 2010, 4, 1790-1798.

(20) Sheng, Z.-H.; Zheng, X.-Q.; Xu, J.-Y.; Bao, W.-J.; Wang, F.-B.; Xia, X.-H. Electrochemical sensor based on nitrogen doped graphene: simultaneous determination of ascorbic acid, dopamine and uric acid. Biosens. Bioelectron. 2012, 34, 125-131.

(21) Wen, Z.; Wang, X.; Mao, S.; Bo, Z.; Kim, H.; Cui, S.; Lu, G.; Feng, X.; Chen, J. Crumpled nitrogen-doped graphene nanosheets with ultrahigh pore volume for high-performance supercapacitor. Adv. Mater. 2012, 24, 5610-5616.

(22) Sui, Z.-Y.; Meng, Y.-N.; Xiao, P.-W.; Zhao, Z.-Q.; Wei, Z.-X.; Han, B.-H. Nitrogen-doped graphene aerogels as efficient supercapacitor electrodes and gas adsorbents. ACS Appl. Mater. Interfaces 2015, 7, 1431-1438.

(23) Li, Y.; Zhao, Y.; Cheng, H.; Hu, Y.; Shi, G.; Dai, L.; Qu, L. Nitrogen-doped graphene quantum dots with oxygen-rich functional groups. J. Am. Chem. Soc. 2012, 134, 15-18.

(24) Qu, D.; Zheng, M.; Zhang, L.; Zhao, H.; Xie, Z.; Jing, X.; Haddad, R. E.; Fan, H.; Sun, Z. Formation mechanism and optimization of highly luminescent $\mathrm{N}$-doped graphene quantum dots. Sci. Rep. 2014, 4, 5294.

(25) Lin, Y.-C.; Teng, P.-Y.; Yeh, C.-H.; Koshino, M.; Chiu, P.-W.; Suenaga, K. Structural and chemical dynamics of pyridinic-nitrogen defects in graphene. Nano Lett. 2015, 15, 7408-7413.

(26) Schiros, T.; Nordlund, D.; Pálová, L.; Prezzi, D.; Zhao, L.; Kim, K. S.; Wurstbauer, U.; Gutiérrez, C.; Delongchamp, D.; Jaye, C.; et al. Connecting dopant bond type with electronic structure in $\mathrm{N}$-doped graphene. Nano Lett. 2012, 12, 4025-4031.

(27) Luo, Z.; Lim, S.; Tian, Z.; Shang, J.; Lai, L.; MacDonald, B.; Fu, C.; Shen, Z.; Yu, T.; Lin, J. Pyridinic N doped graphene: synthesis, electronic structure, and electrocatalytic property. J. Mater. Chem. 2011, 21, 8038-8044.

(28) Telychko, M.; Mutombo, P.; Ondráček, M.; Hapala, P.; Bocquet, F. C.; Kolorenč, J.; Vondráček, M.; Jelínek, P.; Svec, M. Achieving High-Quality Single-Atom Nitrogen Doping of Graphene/ $\mathrm{SiC}(0001)$ by Ion Implantation and Subsequent Thermal Stabilization. ACS Nano 2014, 8, 7318-7324.

(29) Martín-Recio, A.; Romero-Muñiz, C.; Pou, P.; Pérez, R.; Gómez-Rodríguez, J. M. Combining nitrogen substitutional defects and oxygen intercalation to control the graphene corrugation and doping level. Carbon 2018, 130, 362-368.

(30) Martín-Recio, A.; Romero-Muñiz, C.; Pou, P.; Pérez, R.; Gómez-Rodríguez, J. M. Purely substitutional nitrogen on graphene/ $\mathrm{Pt}(111)$ unveiled by STM and first principles calculations. Nanoscale 2016, 8, 17686-17693.

(31) Lu, Y.-F.; Lo, S.-T.; Lin, J.-C.; Zhang, W.; Lu, J.-Y.; Liu, F.-H.; Tseng, C.-M.; Lee, Y.-H.; Liang, C.-T.; Li, L.-J. Nitrogen-doped graphene sheets grown by chemical vapor deposition: Synthesis and influence of nitrogen impurities on carrier transport. ACS Nano 2013, 7, 6522-6532.

(32) Lee, S.-K.; Jang, H. Y.; Jang, S.; Choi, E.; Hong, B. H.; Lee, J.; Park, S.; Ahn, J.-H. All graphene-based thin film transistors on flexible plastic substrates. Nano Lett. 2012, 12, 3472-3476.

(33) Liang, X.; Sperling, B. A.; Calizo, I.; Cheng, G.; Hacker, C. A.; Zhang, Q.; Obeng, Y.; Yan, K.; Peng, H.; Li, Q.; et al. Toward clean and crackless transfer of graphene. ACS Nano 2011, 5, 9144-9153.

(34) Gottardi, S.; Müller, K.; Bignardi, L.; Moreno-López, J. C.; Pham, T. A.; Ivashenko, O.; Yablonskikh, M.; Barinov, A.; Björk, J.;
Rudolf, P.; et al. Comparing graphene growth on $\mathrm{Cu}(111)$ versus oxidized $\mathrm{Cu}(111)$. Nano Lett. 2015, 15, 917-922.

(35) Zhao, S.; Barin, G. B.; Cao, T.; Overbeck, J.; Darawish, R.; Lyu, T.; Drapcho, S.; Wang, S.; Dumslaff, T.; Narita, A.; et al. Optical imaging and spectroscopy of atomically precise armchair graphene nanoribbons. Nano Lett. 2020, 20, 1124-1130.

(36) Vélez-Fort, E.; Pallecchi, E.; Silly, M. G.; Bahri, M.; Patriarche, G.; Shukla, A.; Sirotti, F.; Ouerghi, A. Single step fabrication of Ndoped graphene/Si3N4/SiC heterostructures. Nano Res. 2014, 7, $835-843$.

(37) Wei, D.; Peng, L.; Li, M.; Mao, H.; Niu, T.; Han, C.; Chen, W.; Wee, A. T. S. Low temperature critical growth of high quality nitrogen doped graphene on dielectrics by plasma-enhanced chemical vapor deposition. ACS Nano 2015, 9, 164-171.

(38) Kato, T.; Hatakeyama, R. Direct Growth of Doping-DensityControlled Hexagonal Graphene on SiO2Substrate by Rapid-Heating Plasma CVD. ACS Nano 2012, 6, 8508-8515.

(39) Zhuo, Q.-Q.; Wang, Q.; Zhang, Y.-P.; Zhang, D.; Li, Q.-L.; Gao, C.-H.; Sun, Y.-Q.; Ding, L.; Sun, Q.-J.; Wang, S.-D.; et al. Transfer-free synthesis of doped and patterned graphene films. ACS Nano 2015, 9, 594-601.

(40) Carini, M.; Shi, L.; Chamberlain, T. W.; Liu, M.; Valenti, G.; Melle-Franco, M.; Paolucci, F.; Khlobystov, A. N.; Pichler, T.; MateoAlonso, A. Wall- and Hybridisation-Selective Synthesis of NitrogenDoped Double-Walled Carbon Nanotubes. Angew. Chem., Int. Ed. 2019, 58, 10276-10280.

(41) Krivanek, O. L.; Corbin, G. J.; Dellby, N.; Elston, B. F.; Keyse, R. J.; Murfitt, M. F.; Own, C. S.; Szilagyi, Z. S.; Woodruff, J. W. An electron microscope for the aberration-corrected era. Ultramicroscopy 2008, 108, 179-195.

(42) Li, X.; Cai, W.; An, J.; Kim, S.; Nah, J.; Yang, D.; Piner, R.; Velamakanni, A.; Jung, I.; Tutuc, E.; et al. Large-area synthesis of high-quality and uniform graphene films on copper foils. Science 2009, $324,1312-1314$.

(43) Kozlov, L.; Goldberg, I. Supramolecular interaction patterns in the zinc(II) dichloride and tin(IV) tetrachloride complexes with dipyrido[f,h] quinoxaline-6,7-dicarbonitrile. Acta Crystallogr., Sect. C: Cryst. Struct. Commun. 2008, 64, m123-o501.

(44) Yang, W.; Qiu, Q.-M.; Zhou, L.-L.; Jin, Q.-H.; Zhang, C.-L. An orthorhombic polymorph of pyrazino[2,3-f] [1,10] phenanthroline-2,3dicarbonitrile. Acta Crystallogr., Sect. E: Struct. Rep. Online 2011, 67, o3250-o3251.

(45) Shirley, D. A. High-resolution X-ray photoemission spectrum of the valence bands of gold. Phys. Rev. B 1972, 5, 4709.

(46) Tseng, T.-C.; Urban, C.; Wang, Y.; Otero, R.; Tait, S. L.; Alcamí, M.; Écija, D.; Trelka, M.; Gallego, J. M.; Lin, N.; et al. Charge-transfer-induced structural rearrangements at both sides of organic/metal Interfaces. Nat. Chem. 2010, 2, 374-379.

(47) Lindquist, J. M.; Hemminger, J. C. High-resolution core level photoelectron spectra of solid TCNQ: determination of molecular orbital spatial distribution from localized shake-up features. J. Phys. Chem. 1988, 92, 1394-1396.

(48) Classen, T.; Lingenfelder, M.; Wang, Y.; Chopra, R.; Virojanadara, C.; Starke, U.; Costantini, G.; Fratesi, G.; Fabris, S.; De Gironcoli, S.; et al. Hydrogen and Coordination Bonding Supramolecular Structures of Trimesic Acid on $\mathrm{Cu}(110) \dagger$. J. Phys. Chem. A 2007, 111, 12589-12603.

(49) Tseng, T.-C.; Lin, C.; Shi, X.; Tait, S. L.; Liu, X.; Starke, U.; Lin, N.; Zhang, R.; Minot, C.; Van Hove, M. A.; et al. Twodimensional metal-organic coordination networks of $\mathrm{Mn}-7,7,8,8$ tetracyanoquinodimethane assembled on $\mathrm{Cu}(100)$ : Structural, electronic, and magnetic properties. Phys. Rev. B 2009, 80, 155458.

(50) De Blauwe, K.; Mowbray, D. J.; Miyata, Y.; Ayala, P.; Shiozawa, H.; Rubio, A.; Hoffmann, P.; Kataura, H.; Pichler, T. Combined experimental and $\mathrm{ab}$ initio study of the electronic structure of narrowdiameter single-wall carbon nanotubes with predominant $(6,4),(6,5)$ chirality. Phys. Rev. B 2010, 82, 125444.

(51) Ayala, P.; Miyata, Y.; De Blauwe, K.; Shiozawa, H.; Feng, Y.; Yanagi, K.; Kramberger, C.; Silva, S. R. P.; Follath, R.; Kataura, H.; 
et al. Disentanglement of the electronic properties of metallicityselected single-walled carbon nanotubes. Phys. Rev. B 2009, 80, 205427.

(52) Lv, R.; Li, Q.; Botello-Méndez, A. R.; Hayashi, T.; Wang, B.; Berkdemir, A.; Hao, Q.; Elías, A. L.; Cruz-Silva, R.; Gutiérrez, H. R.; et al. Nitrogen-doped graphene: beyond single substitution and enhanced molecular sensing. Sci. Rep. 2012, 2, 586.

(53) Li, J.; Wang, D.; Wan, L.-J. Unexpected functions of oxygen in a chemical vapor deposition atmosphere to regulate graphene growth modes. Chem. Commun. 2015, 51, 15486-15489.

(54) Susi, T.; Mowbray, D. J.; Ljungberg, M. P.; Ayala, P. Calculation of the graphene $\mathrm{C} 1 \mathrm{~s}$ core level binding energy. Phys. Rev. B 2015, 91, 081401.

(55) Yeh, I.; Lindau, J.-J. Atomic Subshell Photoionization Cross Sections and Asymmetry Parameters; Gordon and Breach: Langhorne, PE (USA), 1993.

(56) Krivanek, O. L.; Chisholm, M. F.; Nicolosi, V.; Pennycook, T. J.; Corbin, G. J.; Dellby, N.; Murfitt, M. F.; Own, C. S.; Szilagyi, Z. S.; Oxley, M. P.; et al. Atom-by-atom structural and chemical analysis by annular dark-field electron microscopy. Nature 2010, 464, 571-574.

(57) Scardamaglia, M.; Struzzi, C.; Osella, S.; Reckinger, N.; Colomer, J.-F.; Petaccia, L.; Snyders, R.; Beljonne, D.; Bittencourt, C. Tuning nitrogen species to control the charge carrier concentration in highly doped graphene. 2D Mater. 2016, 3, 011001.

(58) Wu, S.; Zhao, W.; Yang, X.; Chen, Y.; Wu, W.; Song, Y.; Yuan, Q. Suitable Surface Oxygen Concentration on Copper Contributes to the Growth of Large Graphene Single Crystals. J. Phys. Chem. Lett. 2019, 10, 4868-4874.

(59) Hao, Y.; Wang, L.; Liu, Y.; Chen, H.; Wang, X.; Tan, C.; Nie, S.; Suk, J. W.; Jiang, T.; Liang, T.; et al. Oxygen-activated growth and bandgap tunability of large single-crystal bilayer graphene. Nat. Nanotechnol. 2016, 11, 426-431.

(60) Hao, Y.; Bharathi, M. S.; Wang, L.; Liu, Y.; Chen, H.; Nie, S.; Wang, X.; Chou, H.; Tan, C.; Fallahazad, B.; et al. The role of surface oxygen in the growth of large single-crystal graphene on copper. Science 2013, 342, 720-723.

(61) Liang, T.; He, G.; Huang, G.; Kong, Y.; Fu, W.; Chen, H.; Wang, Q.; Iwai, H.; Fujita, D.; Liu, Y.; et al. Graphene Nucleation Preferentially at Oxygen-Rich $\mathrm{Cu}$ Sites Rather Than on Pure $\mathrm{Cu}$ Surface. Adv. Mater. 2015, 27, 6404-6410.

(62) Robinson, Z. R.; Ong, E. W.; Mowll, T. R.; Tyagi, P.; Gaskill, D. K.; Geisler, H.; Ventrice, C. A. Influence of chemisorbed oxygen on the growth of graphene on $\mathrm{Cu}(100)$ by chemical vapor deposition. J. Phys. Chem. C 2013, 117, 23919-23927.

(63) Moreno-López, J. C.; Mowbray, D. J.; Pérez Paz, A.; de Campos Ferreira, R. C.; Ceccatto dos Santos, A.; Ayala, P.; de Siervo, A. Roles of Precursor Conformation and Adatoms in Ullmann Coupling: An Inverted Porphyrin on $\mathrm{Cu}(111)$. Chem. Mater. 2019, 31, 3009-3017.

(64) Müller, K.; Moreno-López, J. C.; Gottardi, S.; Meinhardt, U.; Yildirim, H.; Kara, A.; Kivala, M.; Stöhr, M. Cyano-Functionalized Triarylamines on Coinage Metal Surfaces: Interplay of Intermolecular and Molecule-Substrate Interactions. Chem.-Eur. J. 2016, 22, 581589.

(65) Haberer, D.; Vyalikh, D. V.; Taioli, S.; Dora, B.; Farjam, M.; Fink, J.; Marchenko, D.; Pichler, T.; Ziegler, K.; Simonucci, S.; et al. Tunable band gap in hydrogenated quasi-free-standing graphene. Nano Lett. 2010, 10, 3360-3366.

(66) Kidambi, P. R.; Bayer, B. C.; Blume, R.; Wang, Z.-J.; Baehtz, C.; Weatherup, R. S.; Willinger, M.-G.; Schloegl, R.; Hofmann, S. Observing Graphene Grow: Catalyst-Graphene Interactions during Scalable Graphene Growth on Polycrystalline Copper. Nano Lett. 2013, 13, 4769-4778.

(67) Teng, C.-C.; Ma, C.-C. M.; Lu, C.-H.; Yang, S.-Y.; Lee, S.-H.; Hsiao, M.-C.; Yen, M.-Y.; Chiou, K.-C.; Lee, T.-M. Thermal conductivity and structure of non-covalent functionalized graphene/ epoxy composites. Carbon 2011, 49, 5107-5116.
(68) Kwon, S.; Seo, H.; Lee, H.; Jeon, K.-J.; Young Park, J. Reversible bistability of conductance on graphene/CuOx/Cu nanojunction. Appl. Phys. Lett. 2012, 100, 123101.

(69) Hermann, K. E.; Van Hove, M. A. LEEDpat, Version 4.2. 2014.

(70) Judd, R. W.; Hollins, P.; Pritchard, J. The interaction of oxygen with $\mathrm{Cu}(111)$ : Adsorption, incorporation and reconstruction. Surf. Sci. 1986, 171, 643-653.

(71) Moritani, K.; Okada, M.; Teraoka, Y.; Yoshigoe, A.; Kasai, T. Reconstruction of $\mathrm{Cu}(111)$ induced by a hyperthermal oxygen molecular beam. J. Phys. Chem. C 2008, 112, 8662-8667.

(72) Jeon, C.; Hwang, H.-N.; Lee, W.-G.; Jung, Y. G.; Kim, K. S.; Park, C.-Y.; Hwang, C.-C. Rotated domains in chemical vapor deposition-grown monolayer graphene on $\mathrm{Cu}(111)$ : an angle-resolved photoemission study. Nanoscale 2013, 5, 8210-8214.

(73) Walter, A. L.; Nie, S.; Bostwick, A.; Kim, K. S.; Moreschini, L.; Chang, Y. J.; Innocenti, D.; Horn, K.; McCarty, K. F.; Rotenberg, E. Electronic structure of graphene on single-crystal copper substrates. Phys. Rev. B 2011, 84, 195443.

(74) Marsden, A. J.; Asensio, M.-C.; Avila, J.; Dudin, P.; Barinov, A.; Moras, P.; Sheverdyaeva, P. M.; White, T. W.; Maskery, I.; Costantini, G.; et al. Is graphene on copper doped? Phys. Status Solidi RRL 2013, 7, 643-646.

(75) Khomyakov, P.; Giovannetti, G.; Rusu, P.; Brocks, G. v.; Van den Brink, J.; Kelly, P. J. First-principles study of the interaction and charge transfer between graphene and metals. Phys. Rev. B 2009, 79, 195425.

(76) Gao, L.; Guest, J. R.; Guisinger, N. P. Epitaxial graphene on $\mathrm{Cu}(111)$. Nano Lett. 2010, 10, 3512-3516.

(77) Park, Y.; Jung, D.; Hwang, H.-N.; Hwang, C.-C. Electronic structure of the Au-intercalated graphene/Ni(111) surface. Curr. Appl. Phys. 2019, 19, 215-218.

(78) Wilson, N. R.; Marsden, A. J.; Saghir, M.; Bromley, C. J.; Schaub, R.; Costantini, G.; White, T. W.; Partridge, C.; Barinov, A.; Dudin, P.; et al. Weak mismatch epitaxy and structural Feedback in graphene growth on copper foil. Nano Res. 2013, 6, 99-112.

(79) Joucken, F.; Tison, Y.; Le Fevre, P.; Tejeda, A.; Taleb-Ibrahimi, A.; Conrad, E.; Repain, V.; Chacon, C.; Bellec, A.; Girard, Y.; et al. Charge transfer and electronic doping in nitrogen-doped graphene. Sci. Rep. 2015, 5, 14564.

(80) Ozawa, K.; Oba, Y.; Edamoto, K. Formation and characterization of the $\mathrm{Cu} 2 \mathrm{O}$ overlayer on $\mathrm{Zn}$-terminated $\mathrm{ZnO}(0001)$. Surf. Sci. 2009, 603, 2163-2170.

(81) Bruneval, F.; Vast, N.; Reining, L.; Izquierdo, M.; Sirotti, F.; Barrett, N. Exchange and correlation effects in electronic excitations of $\mathrm{Cu}_{2} \mathrm{O}$. Phys. Rev. Lett. 2006, 97, 267601.

(82) Shen, Z.-X.; List, R. S.; Dessau, D. S.; Parmigiani, F.; Arko, A. J.; Bartlett, R.; Wells, B. O.; Lindau, I.; Spicer, W. E. Photoemission study of $\mathrm{CuO}$ andCu2O single crystals. Phys. Rev. B 1990, 42, 8081 . 